\title{
The Artificial Paradise
}

\section{A Snapshot of Secular Eschatology in Post-War Sweden}

JOHAN EDDEBO

Johan Eddebo is a Research Fellow in Philosophy of Religion at Uppsala University.

johan.eddebo@crs.uu.se

\section{Introduction}

Mark Fisher famously characterized the late-modern condition applying Jacques Derrida's (1930-2004) concept of hauntology, arguing that contemporary culture is in a tangible sense "haunted" by the memory of the lost futures of modernity. That we are haunted by the collective hopes and aspirations of the radical secular optimism of an earlier era whose promises by and large failed to materialize. ${ }^{I}$ Fisher's argument was essentially that we live with a worldview haunted by the broken promises of our recent past. That we are haunted by the accelerating failure of the utopian ideals that characterized the entire modern project from the Enlightenment onward, and now, in a sense, are stranded in a culture that is forced to somehow come to terms with a deepening void of meaning at its very foundations. This intense search for meaning, then, comes to strongly characterize contemporary ideological and spiritual developments, while encumbering them with the impossible task of recreating tangible hopes for the future, which have lost their material and cultural foundations, often manifesting as a nostalgia of the (past) future:

I. Mark Fisher, Ghosts of My Life: Writings on Depression, Hauntology and Lost Futures, Winchester 2014. 
Let's put it this way: it's easy to say, "Oh, things were great in the 7os, let's go back to the 7os", but I think the real issue is "What kind of future did we expect from the 7os?" I mean, there was a trajectory, and this trajectory was interrupted. And now we find ourselves haunted by this future that we vaguely expected at the time, and that was terminated somewhere during the 8 os. $^{2}$

In discerning this baggage arguably encumbering us in light of Fisher's portrayal, this paper explores the character of such secular hope expressed in the futurology literature in post-war Sweden from 1973 up until the midI990s, a period of comparative optimism not yet chastened by the economic and political crises of the coming decades, and still inspired by the comparatively untarnished potential of Western liberalism and technological development. The purpose is to describe the quality and character of narratives relating to meaning, hope, and human fulfilment found in this genre and to scrutinize them with regard to redemptive and eschatological themes as well as disseminated values and worldview-content in general.

The selection of literature used was based in the two factors of ostensible popular penetration and official representativeness. The two introductory works from the Swedish publisher Bra böcker, included in their popular book bundles, exemplify the first factor, while the succeeding works which relate to, or which in themselves are, governmental publications, stand for the second.

\section{Nostalgia and Redemption}

That nostalgia for the lost futures of yesterday can be a powerful force is evident with regard to today's political landscape. It has, for instance, often been argued that the resurgence of the radical right is fuelled by such psychological and existential factors, and that a perceived void of meaning and the collapse of eschatological points of reference may likewise be relevant factors in terms of worldview formation is highly plausible. ${ }^{3}$ Exploring the character of this void is therefore likely to be helpful in understanding the character and development of present and future worldviews and related cultural processes.

Looking back to the aspirations of the high times of what arguably was the last great period of stability and optimism will therefore provide us with

2. "Long Live K-punk", Nero, 22 November 20I8, https://www.neroeditions.com/long-livek-punk/, accessed 202I-O4-2I.

3. David Barnes, "Going Back Somewhere: Nostalgia and the Radical Right", Centre for the Analysis of the Radical Right, Io August 2019, https:/www.radicalrightanalysis.com/2019/o8/Io/ going-back-somewhere-nostalgia-and-the-radical-right/, accessed 202I-O4-2I. 
an important frame of reference for the formation of narrative hope, meaning, and purpose of contemporary society, if for no other reason than that the painful vacuum of yesteryear's aspirations, the realization of which seem increasingly distant, likely will tend to be filled with something that can promise to meet the particular needs expressed.

That Scandinavia in general and Sweden in particular has been among the most completely secularized societies in the post-war era is a common stereotype. This notion has been challenged during latter years, for example by questioning traditional notions of secularity and a narrow understanding of religion, as well as by concrete sociological developments of a novel character. ${ }^{4}$ Moreover, the very understanding of secularization as desacralization or the demise of spirituality as such has long been challenged. ${ }^{5}$ Nonetheless, the view that Scandinavia is and has been highly secular is not without its merits with regard to the repudiation of traditional forms of religion, as many variables exemplifying secularization qualified thusly have been comparatively pronounced in this region. ${ }^{6}$

Without discussing the applicability of secularism in the broader sense as a general descriptor of Scandinavia and Sweden, this article will focus on and exemplify one such variable. This particular variable has been (and still is) an important factor of the general worldview climate in the modern West, but seems to have been especially pronounced in Swedish culture and a prominent theme both in popular culture and within the framework of ideological state apparatuses. This factor can best be described as a trust or faith in the salvific power of science and progress, and will throughout this paper be referred to as soteriological scientism.

\section{Soteriological Scientism}

Soteriological scientism, broadly considered, is here defined as a form of immanent secular eschatology that places its trust in progress, social and technological, for the fulfilment of human destiny. This fulfilment may regard the collective as well as individuals, and can accordingly be expressed in a wide variety of ways, such as the indefinite prolongation of a person's biological life or the dissemination of the human species throughout the universe. This type of soteriological perspective has been addressed by

4. See, for example, Inger Furseth (ed.), Religious Complexity in the Public Sphere: Comparing Nordic Countries, Cham 2018, https://doi.org/10.1007/978-3-319-55678-9.

5. See Charly Coleman, "Resacralizing the World: The Fate of Secularization in Enlightenment Historiography", The Journal of Modern History 82 (2010), 368-395, https://doi. org/IO.I086/65I6I4.

6. Dyron B. Daughrity, To Whom Does Christianity Belong? Critical Issues in World Christianity, Minneapolis, MN 20I5, I7I-I90, https://doi.org/I0.2307/j.cttI3www9I. 
several prominent scholars, such as Mikael Stenmark, who discussed it under the label of redemptive scientism, ${ }^{7}$ and Mary Midgley (1919-2018), explicating the importance of salvific scientism as a core myth of late modernity. ${ }^{8}$ The substitution of soteriological scientism for Stenmark's redemptive or Midgley's salvific scientism is simply that both salvation and redemption strongly imply a specifically Christian discourse, whereas "soteriological" has a slightly broader import.

Soteriological scientism is related to the general axiological form or function of scientism. Insofar as scientific knowledge on a naturalist framework is taken to provide any meaningful ethical or moral guidance for the right ordering of individuals and society, the notion that science can also direct us in terms of issues of ultimate importance seems to follow. If science can really, in definite terms, tell us something about how we ought to live, this can only be since it is able to tell us to what end we live - or conversely, the meaning and fulfilment of our lives will arguably be found in precisely the observance of whatever ethical conduct science can in some sense support. Thus, soteriological scientism would according to Stenmark's model conceptually relate to epistemic scientism as the latter anchors the ethical responses implied by the framework.

Explicit formulations of soteriological scientism are rarely found in the popular culture espousing it, which rather portrays it in vaguer terms, exhibiting vistas of untold possibility and indefinite cosmic human progress. This is unmistakably true with regard to the material from the Swedish context which has been reviewed, which largely employs a language of insinuation and indirect appeal to the salvific potential of scientific progress, amid the vivid, supporting illustrations thereof. Such a mode of transmission provides a hopeful atmosphere laden with emotion, but quite little in terms of specific propositional claims as to the redemptive prospects of the bright and promising future implied. This makes the material somewhat difficult to interrogate and criticize directly, which is why this paper aims to more clearly explicate the propositional content of such popular scientific material as reviewed. Hopefully, this will enable us to better understand something of the historical propagation of worldview-content within secular Sweden.

The notion of science as the key to the fulfilment of human destiny is hardly novel. It has been a part of the Western consciousness at least since the Renaissance and began to enter popular culture in earnest during the nineteenth century, with the Great Exhibition of I851, the first world's fair

7. Mikael Stenmark, "What Is Scientism?", Religious Studies 33 (1997), I5-32, https://doi. org/IO.IOI7/Soo344I2596003666.

8. Mary Midgley, Science as Salvation: A Modern Myth and Its Meaning, London 1992. 
in the truly international sense, which boasted over six million visitors, as a prominent example thereof. ${ }^{9}$ Still, the thorough penetration of this idea to the extent that something akin to redemptive or salvific scientism ascended to the level of meta-narrative was probably not effected until a century later, in a societal context suffused with rapidly evolving technologies and deeply influenced by secularization in its various forms. ${ }^{10}$

In the following, examples of futurology literature of some importance in the Swedish post-war context is examined with regard to its relation to redemptive and eschatological themes as well as to disseminated values and worldview-content. The methodological approach is a philosophical conceptual analysis and a rational reconstruction based on close reading, as well as an analysis of the narratives and arguments thus recovered with regard to their axiological consequences. ${ }^{\text {II }}$ The method is also supplanted by a visual Barthesian analysis at a few instances as regards the interpretation of images and image rhetoric. ${ }^{\mathrm{I2}}$

\section{Towards the Unknown - 1973}

In 1973, a two-part work on popular history and science entitled I går $i$ dag - $i$ morgon was published in Swedish by Bra böcker, originally written by a set of German academics from both the sciences and the humanities. ${ }^{13}$

Igår $-i d a g-i$ morgon is a work effectively embodying triumphant secularism and technological progressivism while also, somewhat counter-intuitively, being permeated with a pessimism in terms of the future. The publication of the work is situated just before the 1973 oil crisis and the I970s reawakening of the apocalyptic imagination and technological pessimism. At the same time it was published with a somewhat comfortable distance from the horrors of the Second World War and the threat of nuclear annihilation, a setting which possibly has influenced the character of its narrative.

9. See Jeffrey A. Auerbach, The Great Exhibition of I85I: A Nation on Display, New Haven, CT 1999, https://doi.org/I0.2307/j.cttIww3tw8.

Io. Midgley, Science as Salvation, 77-130.

II. Stephen Browne, "Close Textual Analysis: Approaches and Applications", in Jim A. Kuypers (ed.), Rhetorical Criticism: Perspectives in Action, Lanham, MD 2009, 63-77; Jørgen Pedersen, "Habermas' Method: Rational Reconstruction", Philosophy of the Social Sciences 38 (2008), 457-485, https://doi.org/I0.II77/0048393108319024; Karin Johannesson, "Konsekvensprövning", in Mikael Stenmark et al. (eds.), Filosofiska metoder i praktiken, Uppsala 2018, 65-84.

I2. Roland Barthes, Éléments de sémiologie, Paris 1964.

I3. Bra böcker was a popular Swedish publisher founded in 1965, originally dedicated to spreading moderately priced literature among the broader public, whose affordable book bundles were widely read. In 1985, the publisher was awarded the prestigious task of publishing Nationalencyklopedin, the Swedish-language encyclopedia project. 
The work intends to be a comprehensive popular-scientific review of the modern era and its future prospects, and accordingly includes a geographical and geological overview, a general historical orientation, an outline of the art and culture of the modern period, and a survey of modern science and technology, before it embarks on the purely predictive endeavour. Nonetheless, the general tenor of the foundational chapters is directed towards the contemporary liminal age, the edge of the future, which is constantly referenced and kept in mind throughout the text. ${ }^{14}$

A striking feature of the work is the defiant, almost acerbic secularism that permeates the text from beginning to end. The first pages of the opening chapter, discussing cosmogony, categorically reject all non-scientific discussions of cosmogenesis as "mythological". There is no quarter given to any worldview-components that can be associated with anything but a naturalist outlook, and empirical science is taken to be the single and independent key to the objective and disinterested modern knowledge which is mankind's only hope for the future. ${ }^{\text {Is }}$ Throughout the work, this perspective is anchored in a progressivist notion of societal evolution, a view of history according to which the cultures of preceding periods are rendered obsolete by the ones that follow, since they by definition are taken to be more advanced or evolved.

The work predates mainstream assent to postcolonial critiques of the contemporary social order and accordingly presents a thoroughly positive account of industrial development and colonial exploitation. The colonization of, for example, Africa and the Americas is described in neutral terms as the "discovery" of untouched, pristine lands by pioneering Europeans with almost no references to native peoples whatsoever. The particular type of transformation of society towards increasing technological and industrial complexity and economic growth which characterized the modern period is considered the only viable path forward, a narrative within which comparatively primitive cultures are not accorded utility or value. Western techno-industrial civilization is the main agent in the narrative and is implicitly identified with humanity as such, in that it is considered the bearer of mankind's redemptive march towards the unknown future. Any set of challenges associated with this progressive transformation is taken to be surmountable only with regard to further technological development, an idea that is central to the basic eschatological narrative of these works, which tends to further cement the indispensability of technological progress.

I4. Herbert Butze et al., I går - i dag - i morgon: Vår värld genom två sekel I800-2000. I. Gränserna sprängs, Stockholm 1973.

I5. Butze et al., I går - i dag-i morgon, 9-19. 
The juxtaposition between the enlightened West and primitive cultures is sometimes very explicit and clearly tinted with racism. A spread entitled "Between prehistory and utopia" is illustrated with an image of a black woman breastfeeding in a passenger airliner and a photograph showing a group of Peruvian natives in traditional garb set beside a picture of skyscrapers and modernist sculptures. The text remarks how the "primitive people's" acceptance of the "blessings" of civilization and technology is something which characterizes our age, and marvels over how the "negro woman and her child easily blend into the airliner's environment", emphasizing that this, to the reader, should be a counter-intuitive scene. The Peruvian natives' integration into technological society is described as them "doubtlessly having accepted the new 'gods", tacitly portraying a renunciation of their culture and of religion as such. ${ }^{16}$ Here, secularism, neo-colonialism, and progressivism are symbolically intertwined in a narrative of triumphant Western development, evincing conceptual interdependencies that reappear throughout the text.

Wealth disparity is acknowledged as a significant problem in the work, but is again thought of as something that can only be addressed with further progress and industrial expansion, which moreover is presented as the exclusive responsibility of the "industrial nations", the only effective agent. ${ }^{17}$ In relation to wealth disparity, more explicitly racist perspectives are presented. A spread entitled "Is the white man disappearing?" illustrates a threatening "population explosion" of non-white people that somehow must be thwarted, yet with no mention of disparity in consumption and exploitation of resources between the "first" and "third" world. A further section even maintains that it is still an "open question" whether all races have the same innate preconditions to successfully follow in the footsteps of the superior Western industrial society, strongly echoing the associations between race and intelligence purveyed by the eugenics movement.

Religion and autonomist or indigenous decentralization movements are touted as the most significant impediments to progress, aside from issues such as racism, environmental degradation, or, particularly, nuclear war. "Magic still retains its allure over people and not only primitive ones", reads a caption of an illustration of an indigenous people's presumably religious rite ${ }^{\mathrm{I}}{ }^{8}$ Religion is thought to be incompatible with technological and cultural development beyond a certain level, quite reminiscent of Auguste Comte's (1798-1857) model, and although religion is accorded utility in

16. Butze et al., I går - i dag-i morgon, 90-92.

17. Butze et al., I går - i dag - i morgon, 92-95.

I8. Butze et al., I går - $i$ dag-i morgon, 87. 
terms of social and psychological support, it is equated with belief in magic and superstition and considered to retain individuals and societies at pre-modern levels of consciousness. ${ }^{19}$

\section{Good Morning, Future - 1984}

In 1984, the book Godmorgon framtid, written by innovation researcher Bengt-Arne Vedin, was published in Sweden. It contains a number of expertly illustrated technological predictions for the near future, some of which were quite prescient, and is a prime example of the indirect soteriological narrative described in the introduction. ${ }^{20}$ Imaginative technological solutions to all types of problems of life and society are suggested, all with well-researched explanations and theoretical foundations, generally placing them within the realm of scientific feasibility from the perspective of the early 1980 os. Each prediction is put forth with a punctuated rubric in large coloured type, inducing a feeling of definiteness and inevitability of these fruits of progress awaiting us ahead. The tense of the technological stories is generally the present one, giving the reader a sense of their actuality and adjacency.

The general disposition of the narratives is fundamentally hopeful. The future is full of promise and endless possibilities. While there are recurring references to dire challenges humanity must face and overcome, these now more or less function as a loyal antagonist, providing the stories with a meaningful conflict, and do not imply any actual doubt as to which direction history is moving in. The technological society, which exclusively refers to Western industrial states, will bring us towards a bright future, guided by enlightened scientists. Correspondingly, this alliance is the main protagonist in the stories, whereas the people or the citizens are the more or less passive recipients of the bounties and gifts bestowed upon them by the scientists and by technology.

The notion of mankind's control of nature is more emphasized in this particular work compared to the preceding one, which follows from its focus on technological progress and concrete inventions rather than historical development in the broader sense. Nature is, conspicuously, something to be tamed, harnessed, or overcome rather than to associate or cooperate with, as human society progresses towards technological utopia.

Not all technologies predicted have a redemptive character in the sense of safeguarding humanity's future or guiding us towards a happy tomorrow, but many of them do. The ecological crises highlighted in the 1973 work are

19. See Auguste Comte, Cours de philosophie positive: 2. Contenant la philosophie astronomique et la philosophie de la physique, Paris I835.

20. Fred Preston, Ove Pihl \& Bengt-Arne Vedin, Godmorgon framtid, Stockholm 1984. 
rarely mentioned here, yet are constantly present in the background. Several of the possible advances or technological solutions suggested address world hunger or lack of fresh water, while others focus on the extension of human life or augmentation of the body. Industrial megatechnology, in terms of applied scientific knowledge within the framework of industrial modernity towards major transformative projects, is according to this work the means whereby human potential can be realized and the promises of the future fulfilled.

\section{The Information Utopia - the 1980 s and 1990 s}

Alvin Toffler's (1928-2016) The Third Wave, originally published in 1980, was one of the more influential works in terms of popularizing the idea of the coming "information society". Toffler did remarkably well in successfully describing its general outline ahead of his own time..$^{2 \mathrm{I}}$ The work's influence can be seen throughout the Swedish futurology literature through the middle and late I980s, thematically as well as in frequent citations.

The predictions in Toffler's work are generally utopian, yet acknowledge a critical perspective on technology and development, such that it urges us to protect the environment and scrutinize all emerging forms of technology with regard to potential negative consequences well before they are introduced. ${ }^{22}$ Nonetheless, the author, much like those of the previous works, presents societal development, this time into the "third age", the postindustrial information society, as the only possible and ethically viable path forward. Evolutionary technological development in the "upward" sense is necessarily good, and holds the key to safeguarding a decent future society. The post-industrial information society is characterized as integrative and holistic, with individual freedom maximized and production of energy and goods decentralized and renewable. Innovation, increased complexity, and technological progress are still the central features of the narrative, promising a brighter future. In comparison to the previous works reviewed, which mainly focused on the development of a monolithic industrial technology, there is an increased focus on consumer license and individualism, decentralized information technology, and the notion of information as a resource. ${ }^{23}$

Religion is, again, relegated to its supportive function. The author laments the existential desperation of the secular, post-industrial West, yet never addresses the problem as one in terms of the lack of a meaningful

2I. Alvin Toffler, Tredje vågen, Solna 1982.

22. Toffler, Tredje vågen, I26-I3I.

23. Toffler, Tredje vågen, $\mathrm{I} 38-\mathrm{I} 43,243-260$. 
worldview. ${ }^{24}$ Tacitly assuming a scientific naturalism, the author explicitly maintains that life is indeed "meaningless at the cosmic level", while the existential angst of secular society must be addressed purely sociologically, with a structured, regimented life and enduring relationships and connections, something which, for example, regulated religious organizations is thought to be capable of providing when needed. Religious organizations are considered supportive institutional arrangements subsumed under the broader societal framework and its ideological aims. ${ }^{25}$

In connection to the profession of the meaninglessness of existence, the agnostic and relativistic statement "no worldview can ever contain the whole truth" is also expressed, together with the admonition that mankind yet must live as if life were meaningful, that we must construct subjective, although ultimately false, experiences of meaning. Together, these remarks form the almost Lovecraftian sentiment that life indeed is utterly meaningless and that mankind, perhaps for the best, is forever doomed to ignorance of the cosmos' true nature. ${ }^{26}$

A future of cybernetic control systems and a more effective rational organization of society is a more prominent theme in the futurology literature from the 1980s. A project report on the future organization of production and social life by the Swedish Secretariat for Future Studies, Vardagen och världen, published in 1986, is strongly leaning in such a direction in terms of its prognoses. With Toffler's Tredje vagen as an important source, all the options here portrayed as available to us with regard to how society will be organized in the future, are characterized by increased centralized control and a thorough social engineering. ${ }^{27} \mathrm{~A}$ sketch of the Rawlsian social contract functions as the ethical foundation of the theorizing, in principle safeguarding a form of democratic consent in concert with an otherwise intrusive level of government and corporate control of social and family life and the relations of production. ${ }^{28}$ Within the framework of state and corporate organization, the future society is thought to possibly provide a higher level of individual freedom and leisure in parallel with Toffler's increased consumer license, and a future of further sexual liberation is presented as a hopeful possibility. ${ }^{29}$ In this regard, not only the traditional family constellations but the very idea of a cohesive and stable family unit idealized by most forms of religious traditions, is interpreted as obsolete. Religion as an explicit

24. Toffler, Tredje vågen, 325 .

25. Toffler, Tredje vågen, 330-335.

26. Toffler, Tredje vågen, 335 .

27. Vardagen och världen: Programskrift, Stockholm 1986, 48, 85-I2I.

28. Vardagen och världen, 22.

29. Vardagen och världen, 5I-65. 
concept, however, does not feature in the work other than in a brief paragraph where it is described as a potential factor of increased conflict in a multi-cultural society.

Infotopia by Leif Drambo further capitalizes on the concept of the information society. A product of future-research funded by the Swedish Ministry of Finance, Infotopia forecasts a deep and thorough social and cultural revolution in the wake of the transition to the approaching information utopia..$^{30}$ Drambo's proposed visions of a future society is a rationally organized, utilitarian arrangement with maximized consumer license, full employment with reduced working hours and a resulting expansion of leisure, and a new freedom for the development of human potential beyond known limits. Knowledge will become equivalent to political power in a future society governed by rational technocracy. Drambo contends that this future information society has the potential of bringing about something entirely new aside from work, consumption, and production - a new mode of human existence he terms "the art of living", which resembles the Aristotelian ideal of knowledge as the principal telos of humanity. "Science" will provide the technological progress which will liberate mankind from work and toil, enabling us to realize our higher purposes, "thinking and romancing". ${ }^{32}$ Yet Drambo also asserts that each of us are to decide our purposes and what is best for ourselves, maintaining that we need to remain free from ideologies, worldviews, and religions and "laugh" at such convictions, for they bring with them fanaticism, dogmatism, war, violence, and even a disparagement of human dignity. He maintains that we must realize the insufficiency and essential mutability of every perspective, such that "the actual truth is never the final truth". ${ }^{3}$

Further developing the narrative of the information society at the heights of the r990s IT boom, authors Åke E. Andersson's and Peter Sylwan's Framtidens arbete och liv ("Work and life in the future") was released by the major Swedish publisher of education resources, Natur \& Kultur. ${ }^{34}$ It represents the most optimistic assessment of not only the potential of the information society, but of the future in general, of all the literature here reviewed. Throughout the text it is maintained that the technological development of the post-industrial society, in spite of all current issues and problems, eventually will liberate us from all material boundaries and

30. Leif Drambo, Infotopia: Visioner och vägval i informationssambället, Stockholm 1985 , 90-I30.

31. Drambo, Infotopia, I33-137.

32. Drambo, Infotopia, I39.

33. Drambo, Infotopia, I5I.

34. Åke E. Andersson \& Peter Sylwan, Framtidens arbete och liv, Stockholm 1997. 
limitations, and that even natural resources will cease to be relevant in relation to human innovation and knowledge. ${ }^{35}$ These ideas are strongly reminiscent of later narratives regarding transhumanist aspirations to transcendence, and the liberation of human consciousness from its material bindings. Finally, according to Sylwan, in the near future there will be no more resource wars and steadily increasing complexity will enable fully sustainable production at significantly higher levels than what was previously possible. ${ }^{36}$

The work is also, conspicuously, adorned with significantly value-laden statements supporting a secular worldview to the effect that nature and evolution has no purpose and no inherent goal and that all human capacity is a meaningless, random artefact, all intertwined with a scientific and technological discourse lending its authority to such controversial theological claims. ${ }^{37}$ Indeed, even Daniel Dennett's radical eliminative materialist account of human consciousness is affirmed as a matter of course and implied to be an indisputable fact settled by cutting-edge empirical science, which effectively disregards one of the most important issues of contemporary metaphysics, namely the so-called "hard problem of consciousness" in favour of a naturalist presumption.

\section{Conclusions}

The works reviewed almost exclusively uphold technological and scientific progress and development as the only possible solution to the problems of life and society. A belief that science is exclusively capable of providing a path towards a utopian society is present throughout the entire set of works and can be considered the fundamental premise in all of them. The conceptual union of "the future" with increased scientific complexity and technological development is hardly surprising, and has been an almost universal aspect of the Western worldview-environment since the advent of the modern period, but this literature is set apart by the overwhelmingly positive attitude thereto and the strong inclusion of eschatological or neareschatological notions.

The selection of literature was based on the two factors of ostensible popular penetration and official representativeness. Being a small sample, however, it is precarious to conclude anything more than that the marked ideological and theological tendencies embodied in these works were present as a factor in popular and official publications pertaining to future

35. Andersson \& Sylwan, Framtidens arbete och liv, 77-94.

36. Andersson \& Sylwan, Framtidens arbete och liv, I42-I43, 487-493.

37. Andersson \& Sylwan, Framtidens arbete och liv, II3-II4. 
society and its possibilities. Thus we cannot conclude very much regarding the relative strength or general societal influence of these tendencies from this material alone.

It must also be noted that there existed influential counter-narratives during this period, challenging utopian interpretations of technological development, ranging from the deep ecology movement of Arne Næss (I912-2009) to the green anarchism rooted in US transcendentalism. Yet at a deeper structural level, the progressivist narrative functions as a central theme of modern industrial civilization as such, reproduced at a multitude of levels and in relation to various interlocking institutions, all with a positive discursive relevance for such scientistic interpretations of progress as those I have attempted to explore in this paper.

With this being said, it is clear that a radical form of soteriological scientism on naturalist foundations is at the very least strongly represented in the popular and official Swedish futurology of the period.

The objective meaninglessness of human existence in concert with an ontology of scientific naturalism is a recurring theme in the literature reviewed. It is present in the seminal Tredje vaggen as well as in officially sanctioned publications such as Infotopia and Framtidens arbete och liv, which without further explanation or argument explicitly affirm as true an atheistic worldview and the meaninglessness of human existence, together with theologically pregnant, controversial philosophical positions such as radical epistemic relativism or the eliminative materialist account of human consciousness. These and similar positions are in the lastly-mentioned two works adjoined to the main thesis and the narratives of science and technological progress, but merely stated as matters-of-fact without actually being supported, yet while implying the positive relevance of the scientific discourse with regard to these particular theological and philosophical positions. Philosophically, this naturally amounts to a fallacious form of reasoning, while it might very well be rhetorically effective.

The dissemination of such views by both authoritative and prominent publications must almost certainly be considered a factor influencing the formation of the popular worldviews of the period in question. The particular character of the endorsed perspectives thereby shows that official publications, in concert with popular literature, actively served to strengthen non-theistic or naturalistic ideology and worldviews, while explicitly negating perspectives inherent to traditional religion. Such active support must be considered as conflicting with secularism in the sense of the separation of church and state, assuming that this separation excludes official support for particular religious confessions. 
Moreover, these endorsements are particularly significant in that they regard central aspects of worldview formation. The perspectives portrayed as matters-of-fact, rather than merely argued for or stated as plausible positions, concern the meaning of life, the purpose of human existence, and the end-goal of our collective social world, and therefore bear upon the very core of human worldviews rather than more limited ethical issues. Their association to plausible predictions of the near future and to the epistemic status of the scientific institutions arguably also render them a strong rhetorical impetus.

Indeed, all the works reviewed clearly adhere to a scientistic eschatology in the sense that a faith or trust is professed in science and technological progress as provider of the necessary goods of human existence as well as a path towards the end-goal and fulfilment of human community and individual lives. This is a strong endorsement of an influential contemporary worldview, functionally equivalent to a state maintaining that Islam is the true path to salvation or that satori is necessary for people to attain Buddhahood.

An aspect of ethnocentrism is present in much of the literature, aside from the complexes of secularism and the science-religion debate being a particularly Western phenomena. The clearly racist undercurrents that are obvious in the opening 1973 work, Igarr-idag - imorgon, are not evident in the later works to any palpable degree. However, the associations between progress, civilization, power, and ethnicity are implicit in their common premise that Western-led or Western-style technological and economic progress must dictate the shape of our future society, as well as in the more admonitory prescription that Western political institutions are to select a desirable future for mankind. But there are no more open allusions to race in the more recent works.

Due to the prominent role played by societal evolution and future utopias yet to come in the redemptive function of the narratives present in the literature reviewed, I suggest that the concept futuristic soteriological scientism may be used in reference to the particular form of soteriological scientism identified in this brief literature review. It constitutes a form of scientism that emphasizes collective societal evolution and a utopian state of society yet to come, rather than current states of affairs or science's role in stabilizing and maintaining society and/or providing immediate fulfilment for the individual.

As a concluding observation, it must be remarked that such a mythology of immanent salvation on the foundation of human reason and will, building on actual technological and societal advancement, is eminently 
falsifiable. Therefore, it is plausibly more sensitive to challenges in comparison to other soteriologies and prone to be undermined by severe obstacles or disruptions of such perceived advancement. For this reason, our contemporary penchant for nostalgia and radical utopianism in the wake of economic, environmental, and political turmoil may well be a sign of a deeper and quite volatile despondency in the face of a radical loss of meaning and the anxiety of a worldview's broken promises.

The politicized nostalgia of our day, as well as the popularization of transhumanist narratives and the promises of artificial intelligence and increasing technological penetration of the human sphere, can therefore be considered an existential and ideological reaction to the failure of modernity's utopianism. It signifies a doubling down in the faith of human progress in the face of the ostensible frustration of its prophecies, which may well be a source of strife and discord in a future likely laden with various difficult transitions. ${ }^{38}$

I finally wish to recommend further research exploring the influence and the contemporary reception of this kind of soteriological scientism, in the interest of ascertaining its importance as well as producing knowledge of the evolution of worldviews in secular societies and their political, cultural, and psychological impact. Without clearly discerning the conceptual roots of the narratives that guide our aspirations regarding the future, we cannot meaningfully interrogate or challenge them when necessary. If we can fully comprehend the ghosts of past futures, hopefully, their hauntings will both lose some of their ability to terrify and have less power over whatever lies ahead of us.

\section{SUMMARY}

The redemptive function of science is a central facet of contemporary late-modern mythology, which due to the preeminent discursive hegemony of scientism generally goes more or less unexamined. A kind of redemptive scientism has popularly been acknowledged as simply real and unquestionably true, whereas neither the rationale nor the character of these narratives are sufficiently critically examined. Arguably, the trust in scientific redemption has waned in later years, which due to the narratives' dominant role risks engendering profound effects upon culture and society in general, yet these consequences are difficult to understand since we are insufficiently familiar with the myths that cause them. The purpose of this article is to exemplify the reproduction of such secular eschatologies within the framework of the futurology literature from a

38. See John Michael Greer, After Progress: Reason and Religion at the End of the Industrial Age, Gabriola Island 2015. 
period which strongly affirmed and celebrated them. This will hopefully enable us to better understand their character, entrenchment, and ideological consequences, as well as what may follow from a developing rejection of them. 